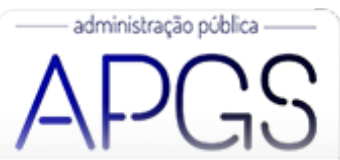

Administração Pública e Gestão Social ISSN: 2175-5787

apgs@ufv.br

Universidade Federal de Viçosa

Brasil

\title{
Práticas de Governança Pública Adotadas pela Administração Pública Federal Brasileira
}

Oliveira Pascoal Correio, Márcia Néa; Vieira de Oliveira Correio, Oderlene

Práticas de Governança Pública Adotadas pela Administração Pública Federal Brasileira

Administração Pública e Gestão Social, vol. 11, núm. 2, 2019

Universidade Federal de Viçosa, Brasil

Disponivel em: http://www.redalyc.org/articulo.oa?id=351558326007

Esta obra está bajo una Licencia Creative Commons Atribución-NoComercial-SinDerivar 3.0 Internacional. 


\title{
Práticas de Governança Pública Adotadas pela Administração Pública Federal
} Brasileira

\author{
Public Governance Practices Adopted by Public Federal Administration in Brazil \\ Prácticas de Gobernanza Pública Adoptadas por la Administración Pública Brasileña
}

Márcia Néa Oliveira Pascoal Correio

Redalyc: http://www.redalyc.org/articulo.oa?

Universidade de Fortaleza, Brasil

$\mathrm{id}=351558326007$

marcianea@edu.unifor.br

Oderlene Vieira de Oliveira Correio

Universidade de Fortaleza, Brasil

oderlene@hotmail.com

Recepção: 29 Abril 2017

Aprovação: 11 Janeiro 2018

Publicado: 01 Abril 2019

\section{Resumo:}

O presente artigo tem como objetivo investigar as práticas de governança pública adotadas pelos órgãos da Administração Pública Federal Brasileira (APFB). Para tanto, fez-se uso de uma abordagem quantitativa do tipo descritiva, viabilizada pela aplicação de técnica estatística descritiva sobre o banco de dados resultante da aplicação do questionário, aplicado em 372 órgãos da APFB. Dentre os resultados, cabe destacar a instituição de um conselho de administração em quase todos os órgãos, porém, as variáveis estudadas, que refletem a efetividade da administração desses conselhos, não são adotadas ou não atingiram um nível de maturidade que permita que o órgão realize a gestão, principalmente, de risco, ou ainda não identificaram a necessidade da adoção de melhores práticas de governança na esfera pública. Portanto, concluiu-se que os órgãos da APFB estão dando os primeiros passos na adoção de melhores práticas de governança corporativa, mas ainda tem muito a avançar.

Palavras-CHaVe: Governança Corporativa, Governança Pública, Administração Pública, Melhores Práticas.

\section{Abstract:}

This article aims to analyze the practices of public governance adopted by the Brazilian Federal Public Sector (BFPS). A quantitative approach was used, of the descriptive type, made possible through the application of a descriptive statistical technique on the database, resulting from the application of a questionnaire applied in 372 BFPS companies. Among the results, it is worth highlighting the establishment of a board of directors in almost all the organs.However, the other variables studied, which reflects the effectiveness of the administration of these councils, are not adopted or have not reached a level of maturity that allows the organ to perform the management, mainly, of risk, or have not yet identified the need to adopt best practices of governance in the public sphere. Therefore, it was concluded that BGPS public bodies are taking the first steps in adopting good corporate governance practices, but there is still much to be done.

KEYWORDS: Corporate Governance, Government Governance, Public Administration, Best Practices.

\section{Resumen:}

Este artículo tiene como objetivo analizar las prácticas de gobernanza pública adoptadas por los órganos de la Administración Pública Federal Brasileña (APFB). Para ello, se hizo uso de un abordaje cuantitativo, del tipo descriptivo, viabilizado por la aplicación de técnica descriptiva sobre el banco de datos resultante de la aplicación del cuestionario, aplicado en 372 órganos de la APFB. Entre los resultados, cabe destacar la institución de un consejo de administración en casi todos los órganos, pero las variables estudiadas, que reflejan la efectividad de la administración de estos consejos, no se adoptan o no alcanzan un nivel de madurez que permita que el órgano realice la gestión, principalmente de riesgo, o aún no identificaron la necesidad de la adopción de mejores prácticas de gobernanza en la esfera pública. Por lo tanto, se concluyó que los organismos públicos de la APFB dan los primeros pasos en la adopción de mejores prácticas de gobierno corporativo, todavía tienen mucho que avanzar.

Palabras clave: Gobernanza Corporativa, Gobernanza Pública, Administración Pública, Mejores Prácticas. 


\section{INTRODUÇÃO}

A partir da Constituic\#a\#o Federal de 1988 os cidadãos brasileiros passaram a ter direitos ine\#ditos, entre eles, o de exercer o controle sobre a administrac\#a\#o pu\#blica, de impor, dentre outras coisas, integridade, transpare\#ncia e prestac\#a\#o de contas aos governantes, bem como de participar diretamente na escolha de políticas pu\#blicas a serem implantadas. Desde então, observa-se uma reestruturação do Estado, com o intuito de torna\#-lo mais orientado para os aspectos sociais, visando consolidar uma "nova" relação entre Estado e sociedade, o que culminou em uma evolução para a noção de governança (Oliveira \& Pisa, 2015). Silveira e Goularte (2016) explanam que, apesar de o tema governança corporativa ser recente, é de suma importância a adoção de suas práticas pela administração pública.

Originalmente pensada para as organizações privadas, com o passar dos anos percebeu-se o anseio da comunidade para que as práticas de governança corporativa pudessem ser aplicadas também às organizações públicas (De Benedicto, Rodrigues, \& Abbud, 2008). A repercussão do tema se deu devido à insatisfação com os modelos até então adotados pelo Estado (Kissler \& Heidemann, 2006), que não davam espaço para as questões sociais e restringiam a participação do cidadão, privilegiando a eficiência e a qualidade da gestão (Paes De Paula, 2005).

Pollit e Bouchaert (2011) relatam que aqueles modelos adotados até então pelos governos não estavam surtindo efeito, já que mesmo quando os cidadãos e outras partes interessadas acreditavam que os serviços eram bons, eles não necessariamente expressavam maior confiança nos governos envolvidos - e quando os serviços melhoravam, a confiança não necessariamente aumentava. Assim, de acordo com Bovaird e Loffler (2003) ficou claro que a administração pública não poderia ser julgada com base apenas na excelência de seus serviços - também teria que ser boa na forma como ela exerceria suas responsabilidades políticas, ambientais e sociais. Com esse esclarecimento deu-se início a uma nova geração de reformas governamentais, que foi rotulada de reformas de "governança pública".

Nesse cenário, Mello (2006) e Tenório (2007) relatam que os governos também têm sido questionados com mais afinco a respeito da sua legitimidade e credibilidade pela sociedade. Clama-se por novas ações eficientes do Estado (Zajdsznajder, 2001), no qual se faz necessário encontrar respostas para questóes como as elevadas despesas públicas, o baixo nível de rendimento, a corrupção, a falta de transparência, entre outros, que muito afetam a administração de quase todos os países do mundo (Matias-Pereira, 2003).

Frente a esse contexto, elaborou-se a seguinte questão de pesquisa: Quais práticas de governança pública os órgãos da Administração Pública Federal Brasileira adotam? Assim, constitui-se objetivo geral da pesquisa investigar as práticas de governança pública adotadas pelos órgãos da Administração Pública Federal Brasileira (APFB).

As práticas de governança corporativa no setor privado constituem um tema de pesquisa comum na academia, mas muito ainda tem que se voltar para práticas de governança corporativa no setor público (Madhani, 2014; Hora, Oliveira, \& Forte, 2014).

A adoção de práticas de governança pública já é realidade em alguns países (Osborne, 2006). No entanto, no Brasil, o setor público encontra-se em processo de transformação, necessitando de mais estudo, pois ainda existem grandes desafios que precisam ser enfrentados quando o assunto é governança pública (MatiasPereira, 2008).

Assim, este estudo se justifica por trazer para a academia uma discussão pouco abordada em pesquisas empíricas, procurando complementar as informações acerca da adoção de melhores práticas de governança pública pelos órgãos da APFB. 


\section{GOVERNANÇA PÚBLICA}

As práticas da gestão privada repercutiram favoravelmente em outros setores, contribuindo para a discussão do tema da governanc\#a corporativa no setor público (Oliveira \& Pisa, 2015). No entender de Kissler e Heidemann (2006), a repercussão do tema ocorreu devido às condições insatisfatórias dos modelos adotados até então pela administração pública. Mello (2006) explana que a abordagem da governança corporativa aplicada ao setor público ganhou destaque quando foi associada à agenda do New Public Management em alguns países anglo-saxões, como Estados Unidos, Reino Unido, Canadá, Austrália e Nova Zelândia.

Os paradigmas de políticas públicas evoluíram significativamente nos últimos trinta anos da "antiga administração pública", que foi parcialmente substituída por uma "nova gestão pública" e agora a uma perspectiva de "governança pública". No entanto, foi observado que certos aspectos de cada abordagem ainda permanecem na maioria dos países e é difícil dizer se, ou quando, haverá um ponto de vista singular sobre o assunto (Bovaird \& Löffler, 2009).

Assim, a governança pública tem sido proclamada como um novo paradigma, distinto da nova gestão pública e da administração pública burocrática ortodoxa. Aplica-se em novos tempos e contextos, marcados pelo pluralismo, complexidade, ambiguidade e fragmentação. Propõe escopos mais amplos, colocandose numa perspectiva mais abrangente de governo e sociedade (Osborne, 2010). Visto desta perspectiva, governança pública é:

um processo de geração de valor público a partir de determinadas capacidade e qualidades institucionais; da colaboração entre agentes públicos e privados na coprodução de serviços, políticas e bens públicos e da melhora do desempenho. Dessa forma, nenhum desses elementos pode ser pensado de forma isolada. (Martins \& Marini, 2014, p. 44).

"O conceito de governanc\#a pública envolve, entre outros aspectos da gestão, transparência, prestação de contas, ética, integridade, legalidade e participação social nas decisões”. (Oliveira \& Pisa, 2015, p. 1263). De acordo com Kissler e Heidemann (2006, p. 480), “[ ..] na\#o existe um conceito u\#nico de governança pu\#blica [..] Pairam du\#vidas na\#o somente sobre as bases de cooperac\#a\#o [...], mas tambe\#m sobre seus resultados." Nesse sentido, buscando ilustrar a amplitude das definições institucionais de governança pública, Oliveira e Pisa (2015) elaboraram o Quadro 1, que contempla algumas definições das entidades às quais dedicam atenção. 
Quadro 1 - definições de governança pública por organizações nacionais e estrangeiras

\begin{tabular}{|c|c|c|}
\hline Ano & Organização & Definição de Governança Pública \\
\hline 2006 & OCDE & $\begin{array}{l}\text { A governança diz respeito aos arranjos formais e } \\
\text { informais que determinam como são tomadas as } \\
\text { decisôes públicas e como são implementadas as } \\
\text { ações públicas, na perspectiva de manter os } \\
\text { valores constitucionais de um paîs em face de } \\
\text { vários problemas, atores e ambientes. }\end{array}$ \\
\hline 2011 & $\begin{array}{l}\text { Tribunal de } \\
\text { Contas da } \\
\text { Uniấo (TCU) }\end{array}$ & $\begin{array}{l}\text { [ ..] governança pública constitui um instrumento } \\
\text { cujo objetivo é assegurar a prestação de contas } \\
\text { pública, contribuindo para reduzir as incertezas } \\
\text { sobre o que ocorre no interior da administração } \\
\text { pública, fornecendo à sociedade e ao Congresso } \\
\text { Nacional uma razoável segurança de que os } \\
\text { recursos e poderes delegados aos administradores } \\
\text { públicos estão sendo geridos mediante açôes e } \\
\text { estratégias adequadas para alcançar os objetivos } \\
\text { estabelecidos pelo poder público, de modo } \\
\text { transparente, em conformidade com os principios } \\
\text { de administração pública, as leis e os } \\
\text { regulamentos aplicáveis. }\end{array}$ \\
\hline 2013 & World Bank & $\begin{array}{l}\text { Governança pública é o conjunto das tradições e } \\
\text { instituiçôes pelas quais a autoridade de um paîs é } \\
\text { exercida. Isso inclui o processo pelo qual os } \\
\text { governos são selecionados, monitorados e } \\
\text { Substituidos, a capacidade do governo de } \\
\text { formular e implementar politicas sólidas de forma } \\
\text { eficaz, e o respeito dos cidadãos e do Estado pelas } \\
\text { instituições que governam as interaçôes } \\
\text { econômicas e sociais entre eles. }\end{array}$ \\
\hline
\end{tabular}

Fonte: Oliveira e Pisa (2015, p. 1269).

Assim, percebe-se que vários elementos de governança são comuns tanto no setor público como no privado, porém, no sistema público precisa-se trabalhar mais a consciência das pessoas para que elas realmente se motivem, tomem posse dos benefícios e aceitem suas finalidades para o alcance dos objetivos (Barret, 2002). Matias-Pereira (2010b, p. 124) acrescenta que, para existir uma boa governança no setor público, deve estar presente o fator "participação proativa de todos os atores envolvidos: dirigentes, políticos, órgãos de controle e, em especial, da sociedade organizada". Todavia, para isso, e\# preciso entender a governanc\# a pu\#blica como "[..] a pra\#tica de uma gesta\#o compartilhada de processos deciso\#rios que conduz, a partir do consenso, as deliberac\#o\#es de uma dada rede, objetivando articular e facilitar ac\#o\#es do projeto de desenvolvimento trac\#ado pelos pro\#prios participantes [..]” (Villela \& Pinto, 2009, p. 1075).

No documento intitulado Governance and Development, do Banco Mundial, Hyden e Court (2002) adotaram um conceito de governança que considera a qualidade da atitude dos gestores, medida em escala de valores que busca o bem comum, o que pressupõe a observância de princípios éticos. Dessa forma, a governança não irá se restringir a cumprir regulamentos, já que constitui um sistema de valores pelo qual as entidades são dirigidas e controladas (Mendes, Bessa, \& Silva, 2015).

Madhani (2014) explana que os princípios de governança corporativa (responsabilização, transparência e conduta ética empresarial) devem ser aplicados tanto no setor privado quanto no setor público. E ressalta que as principais diferenças entre estes setores residem no fato de que o valor agregado pela governança deve atingir o setor privado por meio de lucro, totalmente voltado para a parte financeira, enquanto que o setor público visa principalmente a maximização do bem-estar da sociedade, considerando seus interesses e necessidades. Sobre as metas, devido à limitação de stakeholders, papéis bem definidos, o setor privado consegue esclarecer melhor suas metas; já no setor público, a meta é complexa, pois há variedade de stakeholders (sociedade) e dificuldade em mensurar a meta e se o alcance foi satisfatório. 
Os princípios de governança aplicados ao setor privado foram definidos pelo Cadbury report. No setor público, devido às suas especificidades, o Public Sector Commitee (PSC), que é o comitê do setor público da Federação Internacional de Contadores (IFC), propôs uma definição para os princípios do setor privado que se ajustasse ao contexto do setor público, expostos no Quadro 2.

Quadro 2 - Princípios de governança pública

\begin{tabular}{|l|l|}
\hline Princípio & Definição \\
\hline Transparência & $\begin{array}{l}\text { É exigida a medida que as partes interessadas } \\
\text { (sociedade) tem confiança nas açôes e processos } \\
\text { de tomada de decisão e na gestão das atividades } \\
\text { das entidades do setor público, sendo pública } \\
\text { por meio da consulta e da comunicação de } \\
\text { informaçốes com as partes interessadas, sendo } \\
\text { precisas e claras, conduzindo a ação efetiva, } \\
\text { pontual e tolerável do escrutinio necessário. }\end{array}$ \\
\hline Integridade & $\begin{array}{l}\text { É baseada na honestidade, objetividade, normas } \\
\text { de propriedade, probidade na administração dos } \\
\text { fundos e recursos públicos e na gestão dos } \\
\text { negócios da entidade. É dependente da } \\
\text { efetividade nas estruturas de controle, nos } \\
\text { padrões pessoais e profissionalismo dos } \\
\text { individuos da entidade. É refletida nos } \\
\text { procedimentos de tomada de decisão e na } \\
\text { qualidade dos relatórios financeiros e de } \\
\text { desempenho da entidade. }\end{array}$ \\
\hline $\begin{array}{l}\text { Responsabilidade } \\
\text { em prestar } \\
\text { contas }\end{array}$ & $\begin{array}{l}\text { É processo em que as entidades do setor } \\
\text { público e seus individuos são responsáveis por } \\
\text { suas decisốes e açôes, incluindo a administração } \\
\text { dos fundos públicos e todos os aspectos de } \\
\text { desempenho, e submetendo-se a escrutínio } \\
\text { externo apropriado. }\end{array}$ \\
\hline
\end{tabular}

Fonte: elaborado com base em PSC/IFAC (2001, p. 12).

O setor público, além de ter o compromisso com os princípios básicos de governança, passa a ter também o compromisso com a legalidade e com a legitimidade (Mello, 2006), visto que, na governança pública, é necessária a prestação de contas para com a sociedade, visando manter um relacionamento entre administração, controle e supervisão, como também assegurar os objetivos políticos de forma eficiente e eficaz (Timmers, 2000). Nesse contexto, Slomski (2005), relata que a adoção de melhores práticas de governança pública possibilita que os serviços à comunidade sejam sempre de qualidade, que exista uma continuidade desses serviços e também que viabilizem o acesso ao capital a custos mais baixos.

Com o passar dos anos a Administração Federal Pública deixou de qualificar-se apenas por parâmetros políticos. Os parâmetros técnicos, como transparência, aptidão, competência, princípios morais, passaram a ter maior relevância nesse setor (Brans, 2003; Matias-Pereira, 2003, 2010a). Dias e Cario (2014) ressaltam que é latente a necessidade de instrumentalizar o Estado para que ele possa desenvolver e implantar esse modelo que irá viabilizar a nova relação entre ele e a sociedade, "de modo que os interesses sejam permeados por uma perspectiva também substantiva e o desenvolvimento seja fruto da ação coletiva” (p. 91).

Nesse sentido, Barret (2002) e Marques (2007) apontam seis pontos para conquistar uma satisfatória governança nos órgãos públicos, sendo que três deles são associados a qualidades pessoais de todos da instituição: liderança, integridade e compromisso. Os outros três são o resultado dos processos estipulados: responsabilidade, integração e transparência. Assim, em maio de 2000, surge a Lei Complementar no 101 , a Lei de Responsabilidade Fiscal (LRF), com o objetivo de regular a responsabilidade na gestão fiscal, permitir um debate público mais qualificado, uma melhor fiscalização nas contas públicas e também uma fiscalização minuciosa na parte administrativa da direção, afirmando mais ainda a importância nas ações (Martins \& 
Nascimento, 2001). Vale destacar a sanção da Lei n0 131/2009, a Lei da Transparência, que instituiu a obrigatoriedade de disponibilização de informações em tempo real sobre a execução orçamentária, como também a Lei de acesso à informação de 2011, garantindo que toda informação pertinente às atividades do Estado seja pública, salvo exceções previstas em lei (Abdala \& Torres, 2016).

Outra iniciativa que vale ser ressaltada foi a da Federac\#a\#o Internacional de Contadores (IFAC), por meio do Comitê Setor Pu\#blico (PSC), que publicou em 2001, o estudo 13, com a finalidade de orientar os administradores pu\#blicos e a sociedade sobre princípios e práticas da boa governanc\#a, e também a iniciativa do Tribunal de Contas da Unia\#o (TCU), que lanc\#ou, em 2014, o Referencial Ba\#sico de Governanc\#a Aplica\#vel a O\#rga\# os e Entidades da Administrac\#a\#o Pu\#blica, alinhando a essa perspectiva suas proposic\#o\#es, seus instrumentos e recomendações pra\#ticas (Sauerbronn, 2017).

O fato de a temática normativa presente nas boas práticas de governança ser algo eficiente e legítimo faz com que, cada vez mais, essas práticas sejam disseminadas pelo mundo (Aguilera \& Cuervo-Cazurra, 2004; Fiss, 2008). No entanto, mesmo com a urgência da difusão dessas práticas, e com todas as vantagens que ela traz, tem-se detectado dificuldades em mudar o sistema de governança (Fiss, 2008; Nee \& Sweedberg, 2005; North, 1990), uma vez que necessita de acordos políticos para conseguir modificar o seu sistema e, consequentemente, alterar a legislação (Zattoni \& Cuomo, 2008). Nesse sentido, quando se torna difícil alterar a legislação, alguns países recorrem aos códigos de boas práticas (Enrione, Mazza, \& Zerboni, 2006).

Heinrich, Lynn e Milward (2010) relatam que existe um pequeno e significativo debate sobre se as mudanças na governança estão de fato ocorrendo, já que, infelizmente, é muito mais fácil proclamar “o novo" do que fazer argumentos baseados em evidências, e o novo raramente é visto como uma consequência de uma lógica de mudança histórica ou dependente do caminho. Nesse sentido, Robichau (2011) ressalta que, inegavelmente, a sugestão de usar uma lógica dependente do caminho da mudança governamental merece mais atenção na literatura.

\section{METODOLOGIA}

A pesquisa caracteriza-se, quanto ao tipo, como descritiva (Bryman \& Bell, 2011), uma vez que pretende identificar e descrever os dados encontrados. Quanto à abordagem, caracteriza-se como quantitativa (Neuman, 1997), considerando que fez-se uso de informações numéricas que foram classificadas e analisadas com recursos e técnicas estatísticas descritivas e análise de cluster.

Utilizou-se também de pesquisa documental (Flick, 2015) e consulta a grupos de trabalhos na internet, inserindo-se no contexto teórico-empírico, consubstanciado na análise teórica e na interpretação dos dados e fatos da realidade.

A coleta de dados foi realizada com base em dados secundários disponibilizados no site do Tribunal de Contas da União (TCU). A coleta de dados abrangeu os temas relacionados à governança em órgãos públicos da Administração Pública Federal (APF), tendo como base o levantamento realizado em 2014, mediante a aplicação de questionários em 372 órgãos classificados em segmentos da APF, conforme exposto na Tabela 1.

Tabela 1 - Segmentos das empresas participantes do levantamento de Governança

\begin{tabular}{lll}
\hline Segmento & Descrição & Quantidade \\
\hline EXE-Dest & Empresas públicas federais e as sociedades de economia mista & 63 \\
EXE-Sisp & Organizaçôes que fazem parte do Sistema de Administração dos Recursos & 229 \\
& de Informação e Informática (SISP) & 65 \\
JUD & Organizações do Poder Judiciário & 3 \\
LEG & Organizações do Poder Legislativo & 6 \\
MPU & Organizaçóes que constituem o Ministério Público da União (MPU) & 6 \\
Terceiro Setor & Organizações que não se enquadrem em nenhum dos segmentos anteriores & 6 \\
\hline TOTAL & & 372 \\
\hline
\end{tabular}


Fonte: elaborada pela autora com base nos dados do TCU (2014).

O item selecionado para análise na presente pesquisa trata-se do 1.1, que versa sobre a estrutura de governança pública, que afere objetivamente os aspectos relativos à governança pública. Todas as questões deste item possuem amparo no Referencial Básico de Governança (2014), ABNT NBR ISSO 15999-1:2008, ABNT NBR ISSO 31000:2009 e outros modelos e melhores práticas de governança corporativa que se aplicam ao setor público.

O Referencial Básico de Governança (TCU, 2014), suporta uma parte das questões do item 1.1 por meio de componentes:

- Componente E4 - Estrutura de Governança deve instituir política de delegação, mas também de reservas de poderes que assegure a avaliação, direção e monitoração da organização. Também define papéis e responsabilidades distribuídos entre o Conselho de Administração e a gestão operacional, garantindo a devida segregação de funções, evitando o conflito de interesses e custos de agência (Jensen \& Meckling, 1976). A organização deverá ter seus processos e normas claras para subsidiar a condução da gestão interna de governança e instituir instâncias internas de apoio à governança, indicando o modo de relacionar-se com as demais unidades de governança da organização;

Componente L3 - Liderança Organizacional deve gerenciar a organização, em especial o alcance das metas estabelecidas e o comportamento da Alta Administração e demais gestores;garantir o balanceamento do poder e segregar atividades críticas entre o Conselho de Administração, a Alta Administração e os gestores. A liderança principal deverá responsabilizar-se pelas estruturas de governo, seja interna ou externa, pelo estabelecimento de diretrizes para a gestão e pelo alcance das metas; avaliar os resultados das atividades de controle e de auditoria, atuando para garantir que as providências cabíveis sejam adotadas.

Componente C1 - Gestão de riscos e controle interno - garantir uma estrutura corporativa integrada de gestão de riscos e controle interno.

A norma ABNT NBR ISSO 15999-1:2008 estabelece que a Alta Administração deverá definir uma política de continuidade de negócio alinhado ao propósito da organização, estabelecendo e atendendo requisitos e mantendo a melhoria contínua do Sistema de Gestão de Continuidade de Negócio (SGCN). Já a norma ABNT NBR ISSO 31000:2009 ratifica sobre a definição de uma política de gestão de risco.

No Quadro 3 apresentam-se as questões deste item e a respectiva variável criada para a análise dos indicadores na ferramenta estatística SPSS. 
Quadro 3 - Variáveis selecionadas que aferem aspectos objetivos sobre governança corporativa

\begin{tabular}{|l|l|}
\hline QUESTÃO & Variável SPSS \\
\hline $\begin{array}{l}\text { a. A organização define e comunica } \\
\text { formalmente papéis e responsabilidades para } \\
\text { a governança corporativa. }\end{array}$ & Pap\&Rep \\
\hline $\begin{array}{l}\text { b. A organização dispõe de um comitê de } \\
\text { direção estratégica que auxilia nas decisões } \\
\text { relativas às diretrizes, estratégias, políticas e } \\
\text { no acompanhamento da gestão institucional. }\end{array}$ & \\
\hline $\begin{array}{l}\text { C. A organização realiza avaliações sobre a } \\
\text { definição e compreensão dos papéis e das } \\
\text { responsabilidades organizacionais. }\end{array}$ & AvalPap\&Resp \\
\hline $\begin{array}{l}\text { d. A organização dispõe de um código de ética } \\
\text { formalmente instituido, bem como divulga e } \\
\text { monitora o seu cumprimento. }\end{array}$ & CodEtica \\
\hline $\begin{array}{l}\text { e. A organização dispõe de uma política } \\
\text { corporativa de gestão de riscos formalmente } \\
\text { instituida, como norma de cumprimento } \\
\text { obrigatório. }\end{array}$ & \\
\hline $\begin{array}{l}\text { f. A organização dispõe de uma política } \\
\text { corporativa de gestẫo de continuidade do } \\
\text { negócio formalmente instituida, como norma } \\
\text { de cumprimento obrigatório. }\end{array}$ & \\
\hline
\end{tabular}

Fonte: elaborada pela autora com base nos dados do TCU (2014).

As respostas possíveis para cada item são: "não se aplica", "não adota", "iniciou plano", "adota parcialmente" e "adota integralmente". Foram atribuídos valores de 1 a 5 , respectivamente, para facilitar o entendimento.

Para as análises dos dados utilizou-se a estatística descritiva, com o uso de média, moda, mediana, desvio padrão e contagem de frequência (Moretti \& Campanário, 2009); correlação de Pearson (r) (Figueiredo Filho \& Silva Junior, 2010); e análise de cluster (Corrar, Paulo, \& Dias Filho, 2007).

O coeficiente de correlação de Pearson ( $\mathrm{r}$ ) consiste na associação de duas variáveis pelo compartilhamento de variância. $\mathrm{O}$ modelo linear supóe que o aumento ou a redução de uma unidade na variável $\mathrm{X}$ produz $\mathrm{o}$ mesmo impacto na variável Y (Figueiredo Filho \& Silva Junior, 2010). A correlação de Pearson (r) varia de 1 a 1 , sendo maior a força da relação entre as variáveis, quanto mais próximo o valor estiver da unidade, independente do sinal.

Tendo como valores de referência os seguintes resultados:

0.9 ou mais ou para menos indica uma correlação muito forte.

0.7 a 0.9 positivo ou negativo indica uma correlação forte.

0.5 a 0.7 positivo ou negativo indica uma correlação moderada.

0.3 a 0.5 positivo ou negativo indica uma correlação fraca.

0 a 0.3 positivo ou negativo indica uma correlação desprezível.

Foram utilizados os softwares Microsoft Excel e Statistical Package for the Social Sciences (SPSS).

\section{RESULTADOS E ANÁLISES}

Os resultados da estatística descritiva apurados com base nos dados dos 372 órgãos da Administração Federal Pública Brasileira, para as questões do item 1.1 (Quadro 3) sobre governança pública estão dispostos na Tabela 2 e Tabela 3. Ressalta-se que essas duas Tabelas serão analisadas conjuntamente. 
Tabela 2 - Estatísticas Descritivas - média, mediana, moda e desvio padrão

\begin{tabular}{lllll}
\hline Variável & Média & Mediana & Moda & Desvio Padrão \\
\hline Pap\&Resp & 3,88 & 4,00 & 5 & 1,177 \\
Conselho & 4,13 & 5,00 & 5 & 1,176 \\
AvalPap\&Resp & 3,40 & 4,00 & 2 & 1,241 \\
CodEtica & 3,86 & 4,00 & 5 & 1,202 \\
GRiscoCorp & 2,76 & 2,00 & 2 & 1,052 \\
GContinNeg & 2,77 & 2,00 & 2 & 1,060 \\
\hline
\end{tabular}

Tabela 3 - Estatísticas Descritivas - contagem de frequência

\begin{tabular}{llllllll}
\hline \multirow{2}{*}{ Variáveis } & Não adota (\%) & \multicolumn{5}{c}{ Adota (\%) } \\
\cline { 3 - 6 } & Não se aplica & Não adota & $\begin{array}{l}\text { Iniciou } \\
\text { plano }\end{array}$ & & Parcial & Integral \\
\hline Pap\&Resp & 1,3 & 17,9 & 13,6 & 32,9 & 25,1 & 41,4 & 66,6 \\
Conselho & 2,1 & 13,6 & 9,4 & 25,1 & 18,7 & 55,6 & 74,3 \\
AvalPap\&Resp & 1,6 & 34,2 & 11,8 & 47,6 & 26,5 & 25,4 & 51,9 \\
CodEtica & 0,8 & 21,1 & 11,2 & 33,2 & 24,1 & 42,2 & 66,3 \\
GRiscoCorp & 1,3 & 54,5 & 21,7 & 77,5 & 10,7 & 11,2 & 21,9
\end{tabular}

Atentando para a variável Conselho, na Tabela 2, pode-se afirmar que praticamente todos os órgãos da Administração Federal Pública Brasileira adotam a prática de "instituir um comitê de direção estratégica que auxilia nas decisões relativas às diretrizes, estratégias, políticas e no acompanhamento da gestão institucional”; a média ficou em 4,13, além de a mediana e moda serem 5 , o que sinaliza para a adoção integral dessa prática. $\mathrm{Na}$ Tabela 3 é possível verificar que 74,3\% dos órgãos sinalizaram a adoção dessa prática, cabendo destacar que, deste percentual, 55,6\% adota de forma integral.

Em relação a essa prática, o Referencial Básico de Governança (TCU, 2014) em seu Componente E4, ressalta que a organização deverá ter seus processos e normas claras para subsidiar a condução da gestão interna de governança e instituir instâncias internas de apoio à governança, indicando o modo de relacionar-se com a demais unidades de governança da organização.

Ainda com base na Tabela 2, pode-se observar que, para a mediana 4 (adota parcialmente a prática), tem-se para as variáveis Pap\&Resp e CodEtica, uma média aproximada (3,88 e 3,86 respectivamente) e mediana iguais $(4,00$ e 4,00). Considera-se neste caso que, quando analisadas num contexto geral, a adoção dessas práticas tendem para uma adoção parcial. Mas, se atentarmos para a contagem de frequência, exposta na Tabela 3, é possível averiguar que a maior concentração de respostas está no item "adota integral", com $41,4 \%$ e $42,2 \%$ respectivamente, o que possibilita concluir que essas práticas também vêm sendo adotadas, ou seja, os Órgãos da Administração Federal Pública Brasileira definem e comunicam formalmente papéis e responsabilidades para a governança corporativa e dispõem de um código de ética formalmente instituído, bem como divulgam e monitoram o seu cumprimento. A boa governança requer claras definições de responsabilidade e compreensão do relacionamento entre a sociedade e os gestores dos recursos (PSC/ IFAC, 2001).

Em relação à variável "AvalPap\&Resp”, exposta na Tabela 2, apesar de a média $(3,4)$ sinalizar para o item "iniciou plano”, observa-se na Tabela 3 que a maior concentração de resposta foi na alternativa "não adota”, com $34,2 \%$ das respostas. Vale ressaltar que, afora essa maior concentração de resposta, essa prática vem sendo adotada de forma parcial ou integral por mais da metade dos órgãos da Administração Federal Pública Brasileira, ou seja, $51,9 \%$ dos órgãos realizam avaliações sobre a definição e compreensão dos papéis e das responsabilidades organizacionais. 
Esse resultado vai ao encontro do proposto no Referencial Básico de Governança proposto pelo TCU (2014) em que a estrutura de governança corporativa deve instituir política de delegação, mas também de reservas de poderes que assegurem a avaliação, direção e monitoração da organização.

É pertinente ressaltar ainda que as melhores práticas de governança pública, como dispor de uma política corporativa de gestão de riscos formalmente instituída, como norma de cumprimento obrigatório (GRiscoCorp), e dispor de uma política corporativa de gestão de continuidade do negócio formalmente instituída, como norma de cumprimento obrigatório, vem sendo adotadas por uma minoria na Administração Federal Pública Brasileira (GContinNeg) (Tabela 2 e 3 ).

$\mathrm{Na}$ Tabela 4 tem-se o coeficiente de correlação de Pearson ( $\mathrm{r}$ ), que foi utilizado para a definição das variáveis consistentes para compor os modelos propostos.

Tabela 4: Coeficiente da correlação de Pearson (r)

\begin{tabular}{lllllll}
\hline Variável & Pap\&Resp & Conselho & AvalPap\&Resp & CodEtica & GRiscoCorp & GContinNeg \\
\hline Pap\&Resp & 1 & & & & & \\
Conselho & 0,41 & 1 & & & & \\
AvalPap\&Resp & 0,55 & 0,44 & 1 & 1 & & \\
CodEtica & 0,36 & 0,18 & 0,43 & 0,41 & 1 & \\
GRiscoCorp & 0,38 & 0,22 & 0,47 & 0,30 & 0,51 & 1 \\
GContinNeg & 0,36 & 0,26 & 0,39 & & & \\
\hline
\end{tabular}

Fonte: elaborado pelos autores.

Nada obstante a variável Conselho estar presente em praticamente todos os órgãos da Administração Federal Pública Brasileira (Tabela 2), sendo adotada por $74,3 \%$ dos órgãos, a correlação desta variável (Conselho), Tabela 5, com as demais variáveis de governança pública apresentou uma correlação fraca (Pap\&Resp e AvalPap\&Resp) ou desprezível (CodEtica, GRiscoCorp e GContinNeg), indicando que o fato de existir um Conselho de Administração ou Comitê de Direção Estratégica não faz as práticas esperadas para uma boa governança no poder público dos órgãos pesquisados serem adotadas ou alcançarem um nível de adoção (maturidade) adequado em acordo com a referência proposta pelo TCU (2014) e demais normas da $\mathrm{ABNT}$ e, principalmente, quanto à gestão de riscos e gestão de continuidade de negócio.

Vale destacar a correlação positiva moderada existente entre as variáveis Pap\&Resp e AvalPap\&Resp $(0,55)$, sinalizando que a definição e comunicação formalmente dos papéis e responsabilidades para a governança corporativa apresentam uma relação moderada positiva com a realização e avaliaçóes sobre a definição e compreensão dos papéis e das responsabilidades organizacionais.

Objetivando uma análise mais apurada, buscou-se aplicar aos dados a análise de cluster. No entanto, antes da aplicação, verificou-se a consistência das escalas utilizadas. Nesse sentido, atentando para o exposto na Tabela 5, observa-se que os coeficientes do Alfa de Cronbach não padronizado e padronizado são, respectivamente 0,783 e 0,784 , com base em 6 variáveis. Esses valores demonstram que as escalas utilizadas são consistentes, sendo satisfatórias para a aplicação da análise de cluster, pois os coeficientes do Alfa de Cronbach são superiores aos recomendados pela literatura existente (Rodrigues \& Paulo, 2011).

Tabela 5: Estatística de confiabilidade

\begin{tabular}{l|l|l}
\hline $\begin{array}{l}\text { Cronbach } \\
\text { 's Alpha }\end{array}$ & $\begin{array}{l}\text { Cronbach's Apha } \\
\text { Based on } \\
\text { Standardized Items }\end{array}$ & \\
\hline 0,783 & 0,784 & 6 \\
\hline
\end{tabular}


Atentando para dendrograma (Figura 1) foi possível identificar dois grupos de respostas com características comuns, com similaridade interna e dissimilaridade externa (Corrar et al., 2007).

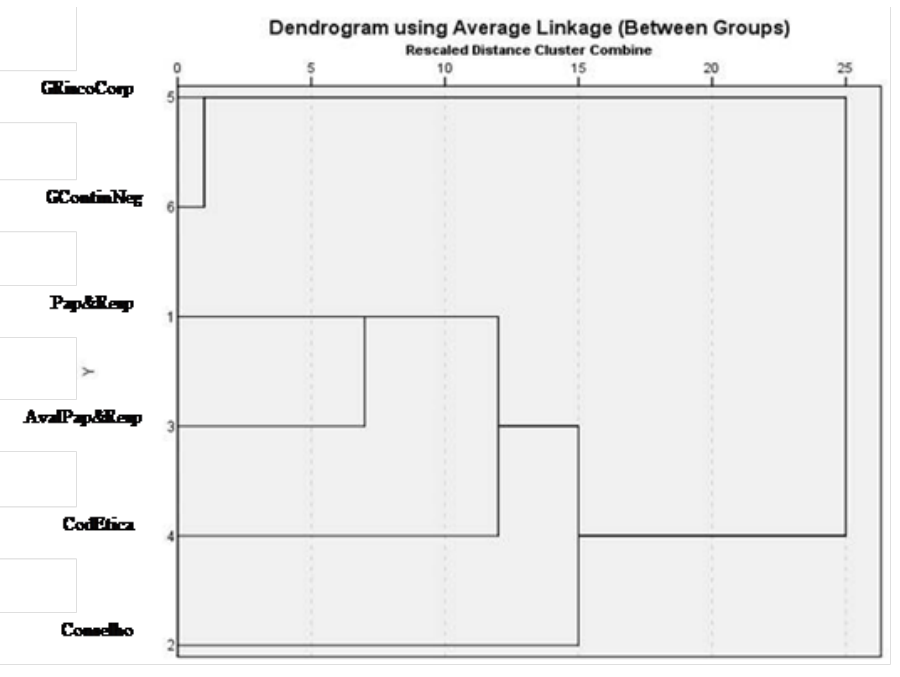

Figura 1- Dendrograma

Analisando as características de cada variável, por cluster, pode-se perceber a similaridade entre as variáveis, conforme exposto na Tabela 6.

O cluster 1 agrega aspectos institucionais em relação a disciplinamentos quanto aos papéis e responsabilidades na gestão da instituição, e que tiveram a maior concentração de respostas na opção "adota integralmente", sinalizando que estas práticas vem sendo adotadas pelos órgãos da Administração Federal Pública Brasileira.

Já o cluster 2, a análise tem cunho confirmatório em relação à similaridade entre as variáveis de Gestão de Riscos Corporativos e Gestão de Continuidade de Negócios, pois para que se trate devidamente os riscos, é necessário que existam planos de contingências a ser executados em eventualidades com base na exposição ao risco, probabilidade e impacto para a organização (Tabela 5).

Tabela 6 - Distribuição das repostas por variável de cada cluster

\begin{tabular}{lllllll}
\hline \multirow{2}{*}{ Cluster } & Segmento & Não se aplica & Não adota & Iniciou & Adota & Adota \\
Parcialmente & integralmente \\
\hline \multirow{4}{*}{1} & Pap\&Resp & 5 & 67 & 51 & 94 & 155 \\
& Conselho & 8 & 51 & 35 & 70 & 208 \\
& AvalPap\&Resp & 6 & 128 & 44 & 99 & 95 \\
& CodEtica & 3 & 79 & 42 & 90 & 158 \\
\hline TOTAL & & 22 & 325 & 172 & 353 & 616 \\
\hline \multirow{2}{*}{ TOTAL } & GRiscoCorp & 5 & 204 & 81 & 40 & 42 \\
\hline
\end{tabular}

Vale destacar que as variáveis do cluster 2 apresentaram a maior concentração de respostas na opção "não adota", ressaltando que os órgãos da Administração Federal Pública Brasileira não estão atentando para a norma da ABNT NBR ISSO 15999-1:2008, que estabelece que a Alta Administração deverá definir uma política de continuidade de negócio alinhado ao propósito da organização, estabelecendo e atendendo 
requisitos e mantendo a melhoria contínua do Sistema de Gestão de Continuidade de Negócio (SGCN), e nem para a norma ABNT NBR ISSO 31000:2009 que ratifica sobre a definição de uma política de gestão de risco.

\section{CONCLUSÃO}

Este trabalho foi desenvolvido com o intuito de investigar as práticas de governança pública adotada pelos órgãos no âmbito da Administração Pública Federal Brasileira por meio de análises descritivas e multivariadas dos dados secundários. As variáveis foram restritas ao item que trata exclusivamente de governança pública, onde as respostas são voltadas para a instituição.

Os resultados apontam que dentre as práticas de governança pública avaliadas pelo Tribunal de Contas da União (TCU), as seguintes vêm sendo adotadas pelos órgãos da Administração Pública Federal Brasileira: define e comunica formalmente papéis e responsabilidades para a governança corporativa (Pap\&Rep); dispõe de um comitê de direção estratégica que auxilia nas decisões relativas às diretrizes, estratégias, políticas e no acompanhamento da gestão institucional (Conselho); realiza avaliações sobre a definição e compreensão dos papéis e das responsabilidades organizacionais (AvalPap\&Resp); e dispõe de um código de ética formalmente instituído, bem como divulga e monitora o seu cumprimento.

Mendes, Bessa e Silva (2015) ressaltam que os conceitos de ética e transparência são essenciais para um Estado que busque, entre outros fatores condicionantes, garantir a confiabilidade e a credibilidade pública das instituições democrática. Nesse sentido, Hyden e Court (2002) ressaltam que esse processo não deve ser de um único ator, pelo contrário, é necessário que todos conciliem projetos e valores com a prática consciente da boa gestão, tendo como base os princípios da governança pública. Assim, de acordo com Girardin (2012) a boa governança servirá como direção e inspiração para a ética política.

Não obstante, alguns órgãos estarem listados em Brasil, Bolsa, Balcão (B3), a análise registra que há que se crescer em maturidade nas estruturas de governança pública e o fato de possuir um Conselho de Administração não retrata que as demais práticas essenciais para uma boa governança sejam adotadas em sua integralidade, haja vista as baixas correlações apresentadas por meio da técnica de Pearson. Vale acrescentar que a existência de um Conselho de Administração que denota que o órgão possui uma efetividade em sua gestão e suas fundamentais funções amparam todo o arcabouço de práticas de governança corporativa não vão contra a expectativa que a governança pública pretende instaurar para que seja devidamente geridos os recursos públicos dentro dos padrões de ética e justiça, contando com um modelo de transparência governamental que atribua credibilidade e confiabilidade aos atos administrativos do poder público perante a população.

Nesse contexto, Matias-Pereira (2010a) explana que, dentre as principais motivações para a transferência das experiências acumuladas pela governança corporativa para o setor público, tem-se as sérias dificuldades que o Estado brasileiro possui para efetivar as suas ações, que na maioria das vezes são morosas e inflexíveis, impactando na qualidade dos serviços públicos ofertados à população. Pelo visto, essa morosidade e inflexibilidade tem também impactado a adoção de melhores práticas de governança corporativa no setor público. Portanto, conclui-se que os órgãos públicos da Administração Pública Federal Brasileira estão dando os primeiros passos na adoção de melhores práticas de governança pública, tendo muito que avançar nesse sentido.

Este trabalho apresenta algumas limitações, tais como, conforme o próprio órgão provedor da pesquisa afirma, risco de não entendimento da questão respondida pelos respondentes. O próprio órgão reconhece que poderá haver má interpretação por parte dos respondentes e as respostas não retratarem de forma fidedigna a realidade, daí a necessidade da validação das respostas mencionada. 
Para futuros estudos, sugere-se ampliar a quantidade de variáveis para um melhor entendimento do cenário atual dos órgãos públicos e observar as mudanças de comportamento sobre a adoção de melhores práticas de governança pública no tempo.

\section{REFERÊNCIAS}

Abdala, P. R. Z., \&Torres, C. M. S. O. (2016). A Transparência como Espetáculo: um análise dos portais de transparência de estados brasileiros. Administração Pública e Gestão Social, 8(3), 147-158, jul.-set.

Aguilera, R. V., \&Cuervo-Cazurra, A. (2004). Codes of good governance worldwide: what is the trigger? Organization Studies, 25(3), 415-443.

Andrade, A., \&Rossetti, J. P. (2006). Governance corporativa: fundamentos, desenvolvimento e tendências. São Paulo: Atlas.

Barret, P. (2002). Achieving better practice corporate governance in the public sector. Melbourne: AM Auditor General for Australia. Disponível em: http://www.anao.gov.au/ uploads/documents/ . Acesso em: 15 nov. 2016.

Brans, M. (2003). Comparative public administration: from general theory to general frameworks. In: Peters, B. G., \&Pierre, J. (Ed.). Handbook of public administration. London: Sage, p. 424-439.

Bovaird, T., \&Loffler, E. (2003). Evaluating the quality of public governance: indicators, models and methodologies. International Review of Administrative Sciences, 69(3), 375-394.

Bovaird, T., \&Lo\#ffler, E. (2009). Public Management and Governance, 2nd ed., New York: Routledge.

Bryman, A., \&Bell. (2011). Business research methods. 3. ed.). New York: Oxford University Press, 2011.

Corrar, L. J., Paulo, E., \&Dias Filho, J. M. (2007). Análise multivariada: para os cursos de administração, ciências contábeis e economia. São Paulo: Atlas.

Davis, G. F. (2005). New directions in corporate governance. Annual Review of Sociology, 31, 143-162.

De Benedicto, S. C., \& Rodrigues, A. C., \& Abbud, E. L. (2008). Governança corporativa: uma análise da sua aplicabilidade no setor público. In: ENCONTRO NACIONAL DE ENGENHARIA DE PRODUÇÃO, v. 28, 2008, Anais ..

Dias, T., \&Cario, S. A. F. (2014). Governanc\#a Pu\#blica: ensaiando uma concepc\#a\#o. Contabilidade, Gesta\#o E Governanc\#a, 17(3), 89-108.

Enrione, A., Mazza, C., \& Zerboni, F. (2006). Institutionalizing codes of governance. American Behavioral Scientist, 49(7), 961-973.

Figueiredo Filho, D. B., Silva Junior, J. A. (2010). Desvendando os Mistérios do Coeficiente de Correlação de Pearson (r). Revista Política Hoje, 18(1).

Fiss, P. C. (2008). Institutions and corporate governance. In R. Greenwood, C. Oliver, K. Sahlin-Andersson, \&R. Suddaby (Eds.), The sage handbook of organizational institutionalism (pp. 389-410). London: Sage.

Flick, U. (2015). Introducing research methodology: A beginner's guide to doing a research project. Sage.

Girardin, B. (2012). Ethics in politics - why it matters more than ever and how it can make a difference. Globethics.net Focus 5. Geneva: Globethics.net - online version.

Grün, R. (2003). Atores e ações na construção da governança corporativa brasileira. Revista Brasileira de Ciências Sociais, 18(52), 139-161.

Hyden, G., \&Court, J. (2002). Governance and development. World Governance Survey Discussion Paper 1. United Nations University, August.

Heinrich, C. J., Lynn, L. E., \&Milward, H. B. (2010). A State of Agents? Sharpening the Debate and Evidence over the Extent and Impact of the Transformation of Governance. Journal of Public Admin- istration Research and Theory 20(Suppl 1), 3-19.

Hora, R.A. A., Oliveira, O. V. , \&Forte, S. H. A. C . (2014). Governança Corporativa no Setor Público e Privado no Contexto Brasileiro: a produção e a evolução acadêmica em dez anos de contribuições. In: Simpósio de Excelência 
em Gestão e Tecnologia - SEGeT, 2014, Resende. Anais do XI SEGeT Simpósio de Excelência em Gestão e Tecnologia.

Jensen, M. C., \&Meckling, W. (1976). Theory of the firm: managerial behavior, agency costs and ownership structure. Journal of Financial Economics, 3(4), 305-360.

Kissler, L., \& Heidemann, Francisco G. (2006). Governanc\#a pu\#blica: novo modelo regulato\#rio para as relac\#o\#es entre Estado, mercado e sociedade? Rev. Adm. Pu\#blica, 40(3), 479-499, maio/jun.

La Porta, R. et al. (2002). Investor protection and corporate valuation. Journal of Finance, Oxford, 57(3).

Linczuk, L. M. W., \&De Oliveira, A. G. (2016). A governança como instrumento para a sustentabilidade da (res) pública: da aplicação no mundo corporativo à Administração Pública. Revista Mineira de Contabilidade, 4(48), 25-30

Madhani, P. M. (2014). Corporate Governance and Disclosure: Public Sector vs Private Sector. SCMS Journal of Indian Management, 11(1), 5-20, mar.

Mare, B. (1995). Preside\#ncia da Repu\#blica. Plano Diretor da Reforma do Aparelho do Estado. Brasi\#lia: Ministe\# rio da Administrac\#a\#o e Reforma do Estado.

Marques, M. C. C. (2007). Aplicação dos princípios da governança corporativa ao sector público. Revista de Administração Contemporânea, Curitiba, 11(2), 11-26, abr./jun.

Martins, H. F., \&Marini, C. (2014). Governança Pública Contemporânea: uma tentativa de dissecação conceitual. Revista TCU, (130), 42-53, maio/ago.

Martins, I. G. da S., \&Nascimento, C. V. do. (2001). Comentários à Lei de Responsabilidade Fiscal. São Paulo: Saraiva.

Matias-Pereira, J. (2003). Reforma do Estado e controle da corrupção no Brasil. Revista de Administração Mackenzie, São Paulo, 4(1), 39-58.

Matias-Pereira, J. (2008). Administração pública comparada. Revista de Administração Pública, Rio de Janeiro, 42(1), 61-82, jan./fev.

Matias-Pereira, J. (2010a). A governança corporativa aplicada no setor público brasileiro. Administração Pública e Gestão Social , Viçosa, 2(1), 109-134, jan./ mar.

Matias-Pereira, J. (2010b). Governanc\#a no setor pu\#blico. Sa\#o Paulo: Atlas.

Mello, G. R. Governança corporativa no setor público federal brasileiro. 2006. Dissertação (Mestrado em Ciências Contábeis) - Universidade de São Paulo, São Paulo, 2006.

Mendes, A.V. C., Bessa, L. F. M., \&Silva, S. A. M. (2015). Gestão da Ética: a experiência da administração pública brasileira. Administração Pública e Gestão Social, Viçosa, 7(1), 2-8, jan.-mar.

Moretti, S. L. do A., \&Campanario, M. de A. (2009). A Produção Intelectual Brasileira em Responsabilidade Social Empresarial Empresarial-RSE sob a Ótica da Bibliometria.

Nee, V., \&Swedberg, R. (2005). Economic sociology and new institutional economics. In C. Ménard \& M. M. Shirley (Eds.), Handbook of new institutional economics (pp. 789-818). Netherlands: Springer.

Neuman, L. W. (1997). Social research methods: qualitative and quantitative approaches. 3. ed. Boston: Allyn \& Bacon.

North, D. C. (1990). Institutions, institutional change, and economic performance. Cambridge: Cambridge University Press.

Oliveira, A. G., \&Pisa, B. J. (2015). IGovP: índice de avaliação da governança pública-instrumento de planejamento do Estado e de controle social pelo cidadão. Revista de Administração Pública, 49(5), 1263-1290.

Osborne, S. P. (2006). The new public governance. Public Management Review, London, 8 (3), 377-387.

Osborne, S. P. (2010). The New Public Governance? Emerging perspectives on the theory and practice of public governance. Abingdon/Reino Unido: Routledge, $431 \mathrm{p}$.

Paes De Paula, A. P. (2005). Administração pública brasileira entre o gerencialismo e a gesta\#o social. Revista de Administração de Empresas, 45(1), 36-49, jan./mar. 
Pollitt, C., \&Bouchaert, G. (2011). Public Management Reform - a comparative analysis new public management, governance, and the neo-weberian state. Oxford.

PSC/IFAC. (2001). Governance in the Public Sector: A Governing Body Perspective International Public Sector Study 13, IFAC.

Robichau, R. W. (2011). The mosaic of governance: creating a picture with definitions, theories and debates. Policy Studies Journal, 39(S1), 113-131.

Rodrigues, A.; Paulo, E. (2011)Introdução à Análise Multivariada. In: Corrar, L. J.; Paulo, E., Dias Filho, J. M. Análise multivariada para os cursos de administração, ciências contábeis e economia. 1 ed. São Paulo: Atlas.

Sauerbronn, F. F. (2017). Governança Pública em Saúde Pós-Reforma Gerencial no Brasil: reconciliando perspectivas para uma análise multinível. Administração Pública e Gestão Social, 9(3), 148-158, jul.-set.

Silveira, N. S. M.; \& Goularte, J. L. L. (2016). Práticas de Governança no Setor Público Municipal: uma análise a partir do estudo 13 do PSC/ IFAC. RAGC, 4(9), 142-157.

Slomski, V. (2005). Controladoria e governança pública. São Paulo: Atlas.

TCU - Tribunal de Contas da União. (2014). Referencial Básico de Governança do TCU - 2014. Acessado em 11 junho 2016 de .

Tenório, F. G. (2007). Cidadania e desenvolvimento local. Rio de Janeiro: FGV; Ijuí: UNIJUÍ.

Timmers, H. (2000). Government governance: corporate governance in the public sector, why and how? In: Fee Public Sector Conference, 9., 2000. Proceedings.

Villela, L. E., \&Pinto, M. C. S. (2009). Governanc\#a e gesta\#o social em redes empresariais: ana\#lise de tre\#s arranjos produtivos locais (APLs) de confecc\#o\#es no estado do Rio de Janeiro. Revista de Administrac\#a\#o Pu\#blica, [S.1.], 43(5), 1.067-1.089.

Zajdsznajder, L. (2001). Ser ético no Brasil. Rio de Janeiro: Gryphus.

Zattoni, A., \&Cuomo, F. (2008). Why adopt codes of good governance? A comparison of institutional and efficiency perspectives. Corporate Governance, 16(1), 1-15

\section{BY-NC-ND}

